\title{
Trends and Contributing Factors of the Change of HIV Prevalence Over Time Among Reproductive Age Group Women in Ethiopia Evidenced by Ethiopian Demographic and Health Survey (EDHS) Data: a Cross-sectional Study: Multivariate Decomposition Analysis.
}

Yilkal Negesse ( $\square$ negeseyilkal@gmail.com )

Mizan Tepi University

Dereje Alemayehu

Mizan Tepi University

Melsew Setegn

Mizan Tepi University

Abebaw Addisu

Mizan Tepi University

Wondimagegn Wondimu

Mizan Tepi University

\section{Smegnew Gichew}

Mizan Tepi University

Biruk Bogale

Mizan Tepi University

Tewodros Yosef

Mizan Tepi University

Gossa Fetene

Mizan Tepi University

\section{Research Article}

Keywords: Trends, HIV, decomposition analysis, EDHS's data

Posted Date: January 15th, 2021

DOl: https://doi.org/10.21203/rs.3.rs-145848/v1 
License: (c) (i) This work is licensed under a Creative Commons Attribution 4.0 International License. Read Full License 
Trends and contributing factors of the change of HIV prevalence over time among reproductive age group women in Ethiopia evidenced by Ethiopian demographic and health survey (EDHS) data: a cross-sectional study: Multivariate decomposition analysis.

Yilkal Negesse $^{1^{*}}$, Dereje Alemayehu², Melsew Setegn ${ }^{3}$, Abebaw Addisu ${ }^{4}$, Wondimagegn Wondimu $^{1}$, Smegnew Gichew ${ }^{5}$, Biruk Bogale ${ }^{1}$, Tewodros Yosef ${ }^{1}$, Gossa Fetene ${ }^{6}$

${ }^{1}$ Department of Epidemiology and Biostatistics, School of Public Health, College of Health Science, Mizan-Tepi University, Mizan-Aman, Ethiopia

2 School of Public Health, College of Health Science Mizan-Tepi University, Mizan-Aman, Ethiopia

${ }^{3}$ Department of Reproductive Health and Nutrition, School of Public Health, College of Health Science Mizan-Tepi University, Mizan-Aman, Ethiopia

${ }^{4}$ Department of Environmental health science, School of Public Health, College of Health Science Mizan-Tepi University, Mizan-Aman, Ethiopia

${ }^{5}$ Department of Human Nutrition, School of Public Health, College of Health Science Mizan-Tepi University, Mizan-Aman, Ethiopia

${ }^{6}$ Department of Midwifery, College of Health Science Mizan-Tepi University, Mizan-Aman, Ethiopia

*Corresponding Author

Email: negeseyilkal@gmail.com (YN) 


\section{Abstracts}

Background: Human immunodeficiency virus remains the leading cause of morbidity and mortality throughout the world. At the beginning of the epidemic, around 76.1 million people were infected and 32 million people died from AIDS-related illnesses in the world. Sub-Saharan Africa regions are the most affected regions and accounted for $67 \%$ of $\mathrm{HIV}$ infections worldwide, and $72 \%$ of the world's AIDS-related deaths.

Objective: To show trends and contributing factors for the change of HIV prevalence over time among reproductive age group women in Ethiopia.

Methods: This study was conducted based on Ethiopian Demographic and Health Surveys data. A total of 10423 in 2005, 15153 in 2011, and 14159 in 2016 women were involved in the study. Multivariate decomposition analysis was performed using the $\underline{\mathbf{m v d c m p}}$ Stata package to identify the contributing factors of change of HIV prevalence over time. The $95 \%$ confidence interval was used for the test of significance.

Results: This study showed that $90.4 \%$ of the change in HIV prevalence over time was attributable to behavioral change over time, particularly in women who were rural residents and not exposed to media. The behavioral change of women who live in rural areas was the major factor for the decline of HIV for the last ten years. The behavioral change of women who hadn't exposure to media contributed $98.4 \%$ to the decline of HIV prevalence over the past ten years.

Conclusion: The prevalence of HIV among reproductive age group women in Ethiopia was significantly declined over the last ten years and the decline was due to behavioral change over time. The major factor for the reduction of HIV prevalence overtime was the behavioral change of rural resident women. Therefore Ethiopian government should primarily focus on the strengthening and scaling up of behavioral change packages related to HIV prevention and control methods.

Keywords: Trends, HIV, decomposition analysis, EDHS's data. 


\section{Introduction}

The human immunodeficiency virus (HIV) is a type of virus that affects the immune system of the human cell and results in a decline in $\mathrm{CD}^{+}$cell count and immune function, which can leads to life-threatening opportunistic infections, and finally acquired immunodeficiency syndrome (AIDS) (1). Human immunodeficiency virus infection remains the leading cause of morbidity and mortality throughout the world. At the beginning of the epidemic, around 76.1 million people were infected and 32 million people died from AIDS-related illnesses in the world (2). Sub-Saharan Africa region is the most affected region by HIV/AIDS and accounted for $67 \%$ of HIV infections worldwide, and for $72 \%$ of the world's AIDS-related deaths (3). Even though the prevalence rate of HIV in Ethiopia is the lowest as compared to East African countries, still more than one million people are living with HIV(4). Several factors have been linked to the risk of HIV infection in sub-Saharan Africa, ranging from individual demographic characteristics (gender, age, marital status) to socioeconomic status (e.g. education, wealth), cultural practices (e.g. religion, circumcision), and sexual behavior risk factors. Available evidence suggests that women in sub-Saharan Africa are disproportionately affected in comparison with men, accounting for $60 \%$ of all HIV infections(5).

In 2002/03 Ethiopia introduced a new initiative program called Health Extension Program (HEP) to provide comprehensive, universal, equitable, and affordable health services for the rural population. The program was provided as sixteen packages focused on health promotion and education supported by demonstration targeting households, particularly mothers and women through the house to house visits(6). based on promotive, preventive, and basic curative services for both communicable and non-communicable diseases (6).

The introduction of antiretroviral programs in Ethiopia has made a tremendous impact in reducing HIV-related deaths and has been available in Ethiopia since 2003. The scale-up of free antiretroviral therapies (ART) services has been one of the greatest achievements of the HIV program response over the last decade (7). Even though still morbidity and mortality due to HIV is high in Ethiopia; the prevalence of HIV among reproductive age group women was decreased from 2005 to 2016 (8). The decrement of HIV prevalence over time could be explained by (a) behavioral change among women (b) change in the proportion of women over time. The question of substantive interest in this context is: how much of the change is actually due to the 
improvement of behavior suggesting the actual decrease in HIV prevalence and how much is due to a compositional change in the population distribution. So to prevent and control HIV, it is necessary to know the source of variation and the contributing factors for the change in prevalence of HIV precisely using an appropriate statistical method of analysis. But there is no evidence at the national level that examines the contributing factors for the change in HIV prevalence over time via decomposition analysis. Therefore, this study aimed to describe trends, identify the factors that contributed positively or negatively to the change in HIV prevalence among reproductive age group women for the last ten years in Ethiopia based on data of 2005, 2011, and 2016 Ethiopian Demographic and Health Surveys.

\section{Methods and Materials}

\section{Data source and population}

We used 2005, 2011, and 2016 Ethiopian Demographic and Health surveys (EDHSs) data. This EDHSs are nationally representative cross-sectional surveys performed in 9 regions and 2 country city administrations every five years. In each of the surveys, stratified two-stage sampling of clusters was carried out. Stratification was achieved by separating each region into urban and rural areas. Accordingly, a total of 21 sampling strata have been created. In the first stage, a total of 539 Enumeration Areas (EAs) for EDHS 2000, 540 EAs for EDHS 2005, and 645 EAs for EDHS 2016 were randomly selected proportional to the EA size. At the second stage, on average 27 to 32 households per EA were selected (9-11). The data was accessed from the Measure DHS website (http://www.dhs program.com) after permission was granted through an online request by explaining the objective of our study. A total weighted sample of 10423, 15153, and 14159 women used in EDHS 2005, 2011, and 2016 respectively for this study. The comprehensive procedure for sampling was described in the complete EDHS report (9-11).

\section{Variables}

The outcome variable of this study was having HIV in their blood (Yes/No). Whereas place of residence, region, marital status, educational level, occupation, sex of household head, desire for children, heard about HIV, and media exposure were considered as independent variables.

\section{Statistical analysis}

After the data set was downloaded from the Measure DHS website (http://www.dhs program.com) the variables of this study were extracted using STATA version 14.2. Before any statistical 
analysis, the data were weighted using sampling weight for probability sampling and non-response to restore the representativeness of the survey and get reliable statistical estimates.

\section{Trends and decomposition analysis}

STATA version 14.2 was used for Editing, recoding, descriptive and multivariate decomposition analysis. After the data were cleaned, categorized, coded, and weighted, we explored the descriptive statistics by using the frequencies and percentages and presented them by using tables and graphs. The trend of HIV prevalence among reproductive age group women was shown by using different characteristics. The trend period was divided into three phases; the first phase (2005-2011), the second phase (2011-2016), and the overall or third phase (2005-2016) to see the differences in HIV prevalence over time. The data from EDHS 2005, 2011, and 2016 were appended together to perform decomposition analysis.

The aim of using decomposition analysis was to compare the difference in two time periods and identify the sources of variations of HIV/AIDS prevalence among 15-49 age group women in Ethiopia. The difference between any two surveys was explained by the compositional changes or characteristics of surveys (endowments), which is explained, and by the effects of those characteristics (coefficients), which is not explained(12). Therefore, the observed change in prevalence of HIV between the two surveys was additively decomposed in the endowment (characteristics) component and coefficient (effect of characteristics) component using the recently developed mvdcmp Stata package. In the nonlinear model, the response variable is a function of a linear combination of predictors and regression coefficients (12).

$$
\mathrm{Y}=\mathrm{F}(\mathrm{X} \beta)=\operatorname{logit}(\mathrm{Y})=\mathrm{X} \beta
$$

Where $Y$ represent the dependent variable

$X$ represents a set of predictor variables

$\beta$ denote set of regression coefficients

The proportion difference in $\mathrm{Y}$ between the two surveys of $\mathrm{A}$ and $\mathrm{B}$ can be decomposed as

$$
\mathrm{Y}_{\mathrm{A}}-\mathrm{Y}_{\mathrm{B}}=\mathrm{F}\left(\mathrm{X}_{\mathrm{A}} \beta_{\mathrm{A}}\right)-\left(\mathrm{X}_{\mathrm{B}} \beta_{\mathrm{B}}\right)(12) \text {. }
$$

Let the recent 2016 EDHS and reference 2005 EDHS datasets can be denoted by A and B respectively. 
For logistic regression, the log-odds or logit of the prevalence of HIV is given by(12).

$$
\begin{aligned}
\operatorname{logit}(\mathrm{A})- & \operatorname{logit}(\mathrm{B})=\mathrm{F}\left(\mathrm{X}_{\mathrm{A}} \beta_{\mathrm{A}}\right)-\mathrm{F}\left(\mathrm{X}_{\mathrm{B}} \beta_{\mathrm{B}}\right) \\
= & \underbrace{\left[F\left(X_{A} \beta_{A}\right)-F\left(X_{B} \beta_{A}\right)\right]+[\underbrace{}_{C}\left(X_{B} \beta_{A}\right)-F\left(X_{B} \beta_{B}\right]}_{\mathrm{E}}
\end{aligned}
$$

Where; $E$ represents endowments, which is explained by characteristics. An endowment is a change in HIV prevalence due to differences in characteristics. $C$ denotes coefficients or effect of characteristics which is unexplained (12). The coefficient is the change in HIV prevalence due to the effect of predictor variables.

The equation can be presented as:

$$
\operatorname{logit}(A)-\operatorname{logit}(B)=\left[\beta_{0 A}-\beta_{0 B}\right]+\sum X_{i j B} *\left[\beta_{i j A}-\beta_{i j B}\right]+\sum \beta_{i j B} *\left[X_{i j A}-X_{i j B}\right]
$$

Where; $\beta_{0 B}$ is the intercept in the regression equation for EDHS 2000

$\beta_{0 A}$ is the intercept in the regression equation for EDHS 2016.

$\beta_{i j B}$ is the coefficient of the $j^{\text {th }}$ category of the $i^{\text {th }}$ determinant in EDHS 2000

$\beta_{i j A}$ is the coefficient of the $j^{\text {th }}$ category of the $i^{\text {th }}$ determinant in EDHS 2016

$X_{i j B}$ is the proportion of the $j^{\text {th }}$ category of the $i^{\text {th }}$ determinant in the EDHS 2000

$X_{i j A}$ is the proportion of the $j^{\text {th }}$ category of the $i^{\text {th }}$ determinant in EDHS 2016

To determine the specific contribution of each independent variable to each component of differences in the prevalence of HIV we partitioned the endowment and coefficients denoted by $C$ and $E$ into a portion of $C_{k}$ and $E_{k}$, which represent the specific contribution of $K^{\text {th }}$ independent variables for each component of $C$ and $E$ respectively.

\section{Results}

\section{Characteristics of the Study Population}

Based on socio-demographic reports of EDHS data, more than $75 \%$ of women were living in rural areas. More than three fourth of the total households; $75.9 \%$ in $2005,75.4 \%$ in 2011 , and $75.8 \%$ in 2016 were led by males. Regarding education, the proportion of maternal higher educational status was $0.7 \%$ in $2005,4.6 \%$ in 2011 , and $5.5 \%$ in 2016. About one-third (34.4\%) of the women had work in 2005. Likewise, in 2011 and 2016, 57.4\% and 47.7 had work respectively. Regarding the marital status of women, $65.7 \%$ in $2005,61.7 \%$ in 2011 , and $64.9 \%$ were married. In all three surveys, more than $93 \%$ of women had heard about HIV. And also 17.6\%, 32.6\%, and $27.5 \%$ of women in 2005, 2011, and 2016 were exposed to media respectively (Table 1). 
Table 1: Frequency and percentage distribution of characteristics of reproductive age group women in Ethiopia.

\begin{tabular}{|c|c|c|c|c|}
\hline \multirow[t]{2}{*}{ Variables } & \multirow[t]{3}{*}{ Characteristics } & \multicolumn{3}{|c|}{ Frequency and percentage distribution of characteristics } \\
\hline & & EDHS 2005 & EDHS 2011 & EDHS 2016 \\
\hline & & No $(\%)$ & No $(\%)$ & No $(\%)$ \\
\hline \multirow{2}{*}{ Residence } & Urban & $2473(23.7)$ & $3848(25.4)$ & $3373(23.8)$ \\
\hline & Rural & $7951(76.3)$ & $11323(74.6)$ & $10788(76.2)$ \\
\hline \multirow{11}{*}{ Region } & Tigray & $1077(10.3)$ & $996(6.7)$ & $984(6.9)$ \\
\hline & Afar & $655(6.3)$ & $136(0.9)$ & $124(0.9)$ \\
\hline & Amhara & $1378(13.2)$ & $4074(26.9)$ & $3115(22)$ \\
\hline & Oromia & 2009 (19.3) & $5350(35.3)$ & $5234(37)$ \\
\hline & Somali & $652(6.2)$ & $351(2.3)$ & $469(3.3)$ \\
\hline & B/Gumuz & $661(6.3)$ & $158(1)$ & $151(1.1)$ \\
\hline & SNNP & $1496(14.3)$ & $2984(19.7)$ & $2670(21)$ \\
\hline & Gambella & $610(5.8)$ & $64(0.4)$ & $40(0.3)$ \\
\hline & Harari & $739(7.1)$ & $51(0.3)$ & $45(0.3)$ \\
\hline & Addis Ababa & $1151(11)$ & $941(6.2)$ & $936(6.6)$ \\
\hline & Dire-Dawa & $612(5.6)$ & $69(0.5)$ & $97(0.7)$ \\
\hline \multirow[t]{4}{*}{ Educational level } & $\begin{array}{l}\text { No formal } \\
\text { education }\end{array}$ & $7508(72)$ & $7642(50.4)$ & $6666(47.1)$ \\
\hline & Primary & $1691(16.2)$ & $5772(38)$ & 4968 (35.1) \\
\hline & Secondary & $1147(11)$ & $1063(7)$ & $1695(12)$ \\
\hline & Higher & $78(0.7)$ & 693 (4.6) & $834(5.9)$ \\
\hline \multirow[t]{2}{*}{ Occupation } & Had work & 3569 (34.4) & 8640 (57.4) & $6751(47.7)$ \\
\hline & Had no work & 6818 (65.6) & 6419 (42.6) & $7410(52.3)$ \\
\hline \multirow[t]{5}{*}{ Marriage } & Married & 6847 (65.7) & 9364 (61.7) & $9184(64.9)$ \\
\hline & Never married & $2505(24)$ & $4171(27.5)$ & $3693(26.1)$ \\
\hline & Separated & $191(1.8)$ & $316(2.1)$ & $216(1.5)$ \\
\hline & Divorced & $489(4.7)$ & $819(5.4)$ & $679(4.8)$ \\
\hline & Widowed & $393(3.8)$ & $501(3.3)$ & $391(2.8)$ \\
\hline \multirow{2}{*}{$\begin{array}{l}\text { Sex of household } \\
\text { head }\end{array}$} & Male & 7909 (75.9) & 11445 (75.4) & $10731(75.8)$ \\
\hline & Female & $2514(24.1)$ & $3725(24.6)$ & 3430 (24.2) \\
\hline \multirow{2}{*}{$\begin{array}{l}\text { Desire for } \\
\text { children }\end{array}$} & Yes & $5867(57.8)$ & $9485(65.3)$ & 8417 (65.4) \\
\hline & No & $4307(42.3)$ & $5047(34.7)$ & 4445 (34.6) \\
\hline \multirow[t]{2}{*}{ Media exposure } & Yes & 1827 (17.6) & $4923(32.6)$ & $3901(27.5)$ \\
\hline & No & $8583(82.4)$ & $10194(67.4)$ & $10261(72.5)$ \\
\hline \multirow[t]{2}{*}{ Heard about HIV } & Yes & $9453(90.3)$ & $14655(96.6)$ & $13168(93)$ \\
\hline & No & $1009(9.7)$ & $514(3.4)$ & $993(7)$ \\
\hline
\end{tabular}




\section{Overall trends of HIV prevalence over time among reproductive age group women in Ethiopia}

Ethiopia has been shown a decrement in HIV prevalence among women over the study period, from $1.45 \%$ in 2005 to $0.85 \%$ in 2016 (Fig1).

Figure 1: Trends of HIV prevalence among women in Ethiopia from 2005 to 2016. Trends of HIV prevalence over time in Ethiopia by selected characteristics

The trends of HIV prevalence among reproductive age group women showed variation based on different characteristics. HIV prevalence decrement was observed in most of the characteristics and increment in some of the characteristics in each phase. Among rural residents, the largest decrement was observed during the first phase of the study period (2005-2011) with $0.6 \%$ point change followed by the second phases (2011-2016) with $0.1 \%$ point changes and the overall change (2005-2016) was $0.1 \%$ point change. Similarly, based on region, the largest decrement in the first phase was observed in Benishangul-Gumuz regional state with $1.4 \%$ point change followed by southern nation nationalities and people of Ethiopia (SNNP) regional state with $0.6 \%$ point change. On the contrary, the largest increment was observed in the Gambella region and Addis Ababa city administration (Fig 2). Almost all regions showed a decrement in HIV prevalence in the year 2016 as compared to the year 2011(Fig2). In the second phase, the prevalence of HIV was decreased in Gambella regional state by $2.2 \%$ point change, in Benishangul-Gumuz by $0.4 \%$ point change, and in Tigray by $0.3 \%$ point change. In the third phase (overall phase) it was increased by $2.3 \%, 1.9 \%$, and $1.1 \%$ point change in Addis Ababa, DireDawa, and Afar regional state respectively. On the other hand, the overall change in a decrement of HIV prevalence based on the region was higher in Benishangul-Gumuz regional state with 1.8\% point change followed by southern nation nationalities and people of Ethiopia (SNNP) regional state with $1.2 \%$ point change (Table 2 ).

Figure 2: Trends of HIV prevalence in Ethiopia from 2005 to 2016 
Table 2: Trends of HIV prevalence among reproductive age group women by selected characteristics over time in Ethiopia. 


\section{Decomposition analysis}

Overall from 2005 to 2016, there has been a significant decline in the prevalence of HIV in Ethiopia. The overall decomposition result showed that $90.4 \%$ of the decline in the prevalence of HIV over time was due to a difference in the effects of characteristics (behavioral difference or change) between the surveys. About $9.6 \%$ of the decline was due to differences in characteristics (compositional factors) but the change due to differences in characteristics (compositional factors or change in population proportion) was not significant (Table3).

Residence of women and exposure to media showed a significant effect on the decline of HIV prevalence over time. Keeping compositional changes constant, changes in the behavior of women who live in rural areas contributed more than $100 \%$ to the decline of HIV prevalence over the past ten years as compared to women who live in the urban areas. Similarly, behavioral change of women who were exposed to media contributed $98.4 \%$ to the decline of HIV prevalence for the last ten years as compared to women who were not exposed to media (Table 3). 
Table 3: Decomposition of change in HIV prevalence among reproductive age group women in Ethiopia, from 2005 to 2016

\begin{tabular}{|c|c|c|c|c|c|}
\hline \multirow[t]{2}{*}{ Variables } & \multirow[t]{2}{*}{ Characteristics } & \multicolumn{2}{|c|}{ Difference due to characteristics } & \multicolumn{2}{|l|}{ Difference due to coefficient } \\
\hline & & Coef & Pct. & Coef & Pct. \\
\hline \multirow[t]{2}{*}{ Residence } & Urban (ref) & 1 & & 1 & \\
\hline & Rural & $-0.0001[-0.001,0.0003]$ & 1.9 & $-0.006 *[-0.01,-0.02]$ & 106.2 \\
\hline \multirow[t]{2}{*}{ Occupation } & Had work (ref) & 1 & & 1 & \\
\hline & Had no work & $0.0001[-0.0004,0.0006]$ & -1.6 & $0.002[-0.001,0.005]$ & -37.7 \\
\hline \multirow[t]{4}{*}{ Educational level } & $\begin{array}{l}\text { No formal } \\
\text { education }\end{array}$ & 1 & & 1 & \\
\hline & Primary & $0.0000[-0.0004,0.0004]$ & 3 & $0.0005[-0.001,0.002]$ & -9.7 \\
\hline & Secondary & $-0.0000[-0.000,0.0002]$ & 0.2 & $0.0002[-0.001,0.001]$ & -4.1 \\
\hline & Higher (ref) & $-0.000[-0.000,0.001]$ & 0.9 & $0.000[-0.000,0.001]$ & -0.1 \\
\hline \multirow[t]{5}{*}{ Marriage } & Married (ref) & 1 & & 1 & \\
\hline & Never married & $-0.0000[-0.0000,0.0001]$ & 0.004 & $-0.0003[-0.001,0.0007]$ & 5.7 \\
\hline & Separated & $0.0000[-0.0000,0.0001]$ & -0.4 & $0.0000[-0.0002,0.0002]$ & -0.4 \\
\hline & Divorced & $-0.0000[-0.0000,0.0000]$ & 0.01 & $-0.0001[-0.0004,0.0002]$ & 2.02 \\
\hline & Widowed & $0.0000[-0.0001,0.0001]$ & -0.3 & $-0.0000[-0.0004,0.0003]$ & 0.7 \\
\hline \multirow{2}{*}{$\begin{array}{l}\text { Sex of household } \\
\text { head }\end{array}$} & Male (ref) & 1 & & 1 & \\
\hline & Female & $-0.0000[-0.0000,0.0000]$ & 0.001 & $-0.0003[-0.001,0.0007]$ & 5.6 \\
\hline \multirow{2}{*}{$\begin{array}{l}\text { Desire for } \\
\text { children }\end{array}$} & No (ref) & 1 & & 1 & \\
\hline & Yes (ref) & $0.0001[-0.0004,0.0001]$ & -2.4 & $-0.001[-0.004,0.0006]$ & 25.1 \\
\hline \multirow[t]{2}{*}{ Media exposure } & Yes (ref) & 1 & & 1 & \\
\hline & No & $-0.0002[-0.001,0.0005]$ & 2.8 & $-0.006 *[-0.01,-0.0003]$ & 98.4 \\
\hline \multirow[t]{2}{*}{ Heard about HIV } & Yes (ref) & 1 & & 1 & \\
\hline & No & $-0.0000[-0.0002,0.0001]$ & 0.6 & $-0.0006[-0.0005,0.002]$ & -10.2 \\
\hline Constant & & & & $0.01[-0.02,0.2]$ & -91.2 \\
\hline
\end{tabular}




\section{Discussion}

Human immunodeficiency virus infection remains the leading cause of morbidity and mortality throughout the world. At beginning of the epidemic, more than 76.1 million people were infected and 32 million people died from AIDS-related illnesses in the world (2). Ethiopia is one of the Sub-Saharan countries and is known for the epidemic of HIV.

The overall prevalence of HIV among reproductive age group women in Ethiopia was found 1.45, 1.5, and 0.85 in 2005, 2011, and 2016 respectively. The decline from 1.45 [95\% CI 1.2, 1.7] in 2005 to $0.85[0.07,1]$ in 2016 was significant. This value is lower as compared to the pooled estimates of the Sub-Saharan Africa regions (13). This variation could be due to the launching of the Health Extension Program (HEP), improving access to health care, implementation of different programs, including education and stigma-reduction programs, behavior change initiatives, and expansion of HIV testing for all age groups across the territory. And also $90 \%$ of people who know their status receiving treatment in Ethiopia reached 90\%; in which Ethiopia achieved one of the targets on the HIV treatment cascade: 90\% of people living with HIV (PLHIV) knowing their HIV status, $90 \%$ of people who know their status receiving treatment, and $90 \%$ of people on treatment having a suppressed viral load (14). The country also has committed to reducing new HIV infections by 50 percent by 2020 and to ending AIDS as a public health threat by 2030. This is reflected in the Country's Health Sector Transformation Plan II 2015-2020, where one of the major indicators is a reduction of HIV incidence rate(15).

When we decompose the change of HIV prevalence over time, the behavioral change of the respondents between the surveys contributed $90.4 \%$ to the decline of HIV prevalence over the last ten years. Surprisingly behavioral change of rural resident women contributed more than $100 \%$ to the change of HIV prevalence over time as compared to urban residents. This could be due to the increment of access to health facilities, access to transportation, and the government's commitment to improving awareness of the community through health education and enabling them to use health services. In addition to this increased access to information and education over time through health extension workers help rural residents to know about the negative health consequences of HIV $(16,17)$.

The behavioral change of women who were not exposed to media contributed $98.4 \%$ for the change of HIV prevalence over the last ten years. Even though they didn't have access either to Television, Radio, Newspapers, or Internet, now a day's information is near to their house in all rural areas of Ethiopia. Because, in addition to health extension workers, many governmental and 
non-governmental organizations work closely with the community to reduce the prevalence and negative impacts of HIV by giving health education about HIV prevention, and control methods $(18,19)$.

\section{Strength and limitations of the study}

This study had several strengths. The first is, the study was based on nationally representative large datasets and all estimates of the study were done after the data were weighted for probability sampling and non-response. Therefore it had adequate statistical power and generalized to all women in Ethiopia. Lastly, multivariate decomposition was applied to identify factors contributing to the change of HIV prevalence over time in Ethiopia. As a limitation, some variables were not collected in all EDHS's data like wealth index, and are not used for decomposition analysis.

\section{Conclusion and recommendations}

The prevalence of HIV among reproductive age group women in Ethiopia was significantly declined over the last ten years and the decline was due to differences in coefficients (behavioral changes) between the surveys. Behavioral changes of women who live in rural areas and are not exposed to media over time were the source of the decrease in HIV prevalence over the last ten years in Ethiopia. Therefore Ethiopian government should primarily focus on the strengthening and scaling up of behavioral change packages related to HIV prevention and control methods.

\section{Abbreviations}

Coef: Coefficient; DHS: Demographic Health Survey; EA: Enumeration Area; EDHS: Ethiopian Demographic and Health Survey; HIV: Human Immune deficiency Virus; Pct: Percent.

\section{Declarations}

\section{Ethics approval and consent to participate}

Ethical clearance for the survey (2000-2016) was provided by the Ethiopian Health and Nutrition Research Institute (EHNRI) Review Board and the National Research Ethics Review Committee (NRERC) at the Ministry of Science. Respondents were informed about the survey and verbal consent was taken. The detail about ethical approval and consent to participate available in the EDHS's report(20).

\section{Consent for Publication}

Not applicable Availability of Data and Materials 
The EDHS data sets are open and can be accessed from the Measure DHS website (http://www.dhs program.com) through an online request by explaining the objective of the study. The datasets analyzed during the current study are available from the corresponding author upon reasonable request.

\section{Conflict of Interests}

The authors declare that they have no competing interests.

\section{Funding}

We did not receive any funds for this research.

\section{Authors' Contribution}

YN, DA, MS, WW, AA, SG, BB, TY, and GF were involved in this study from the inception to design, acquisition of data, data cleaning, data analysis and interpretation, and drafting and revising of the manuscript. YN prepared the final draft of the manuscript. All authors read and approved the final manuscript.

\section{Acknowledgments}

We, authors, acknowledge the Demographic and Health Surveys (DHS) Program funded by the U.S. Agency for International Development (USAID) for the accusation of the dataset.

\section{References}

1. Fisher BJ, Daugherty LC, Einck JP, Suneja G, Shah MM, Dad LK, et al. Radiation oncology in Africa: improving access to cancer care on the African continent. International Journal of Radiation Oncology• Biology• Physics. 2014;89(3):458-61.

2. Global H. AIDS statistics-2018 fact sheet. 2019.

3. HIV/AIDS JUNPo, Organization WH. AIDS epidemic update, 2009: UNAIDS; 2009.

4. CSA. Data from the 2011 Ethiopia Demographic and Health Survey. Adis Ababa; 2011.

5. Organization WH. Status of global HIV epidemic. http://whqlibdoc who int/unaids/2008/9789291737116_eng_Chapter2A pdf. 2008.

6. Argaw H. The Health Extension Program (HEP) of Ethiopia: Summary of Concepts, Progress, Achievements and Challenges. Addis Ababa: WHO Ethiopia Country Office. 2007.

7. Dorrucci M, Colarusso L, Regine V, Giambenedetto S, Perri G, Castelli F, et al. Combined Antiretroviral Therapy (CART) Reduces AIDS-Related and Non-AIDS-Related Mortality: A Temporal Analysis from Time of Seroconversion (SC). J AIDS Clin Res. 2015;6(523):2.

8. Kibret GD, Ferede A, Leshargie CT, Wagnew F, Ketema DB, Alebel A. Trends and spatial distributions of HIV prevalence in Ethiopia. Infectious diseases of poverty. 2019;8(1):90.

9. CSAEaO M. Ethiopia Demographic and Health Survey 2000. Addis Ababa, Ethiopia and Calverton, Maryland, USA Central Statistical Authority and ORC Macro., 20012000.

10. CSACEal. Ethiopia Demographic and Health Survey 2016. AddisAbaba, Ethiopia, and Rockville, Maryland, USA: CSA and ICF; 2016.

11. OM C. Ethiopia demographic and health survey 2005. Addis Ababa,Ethiopia and Calverton, Maryland USA: central statistics agency and ORC Macro; 2005. 
12. Powers DA, Yoshioka H, Yun M-S. mvdcmp: Multivariate decomposition for nonlinear response models. The Stata Journal. 2011;11(4):556-76.

13. Eaton JW, Rehle TM, Jooste S, Nkambule R, Kim AA, Mahy M, et al. Recent HIV prevalence trends among pregnant women and all women in sub-Saharan Africa: implications for HIV estimates. AIDS (London, England). 2014;28(4):S507.

14. Assefa Y, Gilks CF, Dean J, Tekle B, Lera M, Balcha TT, et al. Towards achieving the fast-track targets and ending the epidemic of HIV/AIDS in Ethiopia: successes and challenges. International Journal of Infectious Diseases. 2019;78:57-64.

15. Office FHAPaC. HIV Prevention in Ethiopia National Road Map 2018 - 2020

Adis Ababa; 2018.

16. Burgoyne AD, Drummond PD. Knowledge of HIV and AIDS in women in sub-Saharan Africa. African Journal of Reproductive Health. 2008;12(2):14-31.

17. Shiferaw Y, Alemu A, Girma A, Getahun A, Kassa A, Gashaw A, et al. Assessment of knowledge, attitude and risk behaviors towards HIV/AIDS and other sexual transmitted infection among preparatory students of Gondar town, north west Ethiopia. BMC research notes. 2011;4(1):505.

18. Kloos H, Wuhib T, Mariam DH, Lindtjorn B. Community-based organizations in HIV/AIDS prevention, patient care and control in Ethiopia. Ethiopian Journal of Health Development. 2003;17(4).

19. (CRDA) CRaDA. Compilation of Good Practices of Selected NGOs Working on HIV/AIDS Addis Ababa, Ethiopia2006.

20. EDHS E. demographic and health survey 2016: key indicators report. The DHS Program ICF. 2016.

\section{Appendixes}

\section{Figure Legends}

Figure1: Trend of HIV prevalence among reproductive age group women in Ethiopia from 2005 to 2016.

Figure2: The trends of HIV prevalence among reproductive age group women over time across regions in Ethiopia from 2005 to 2016. 
Figures

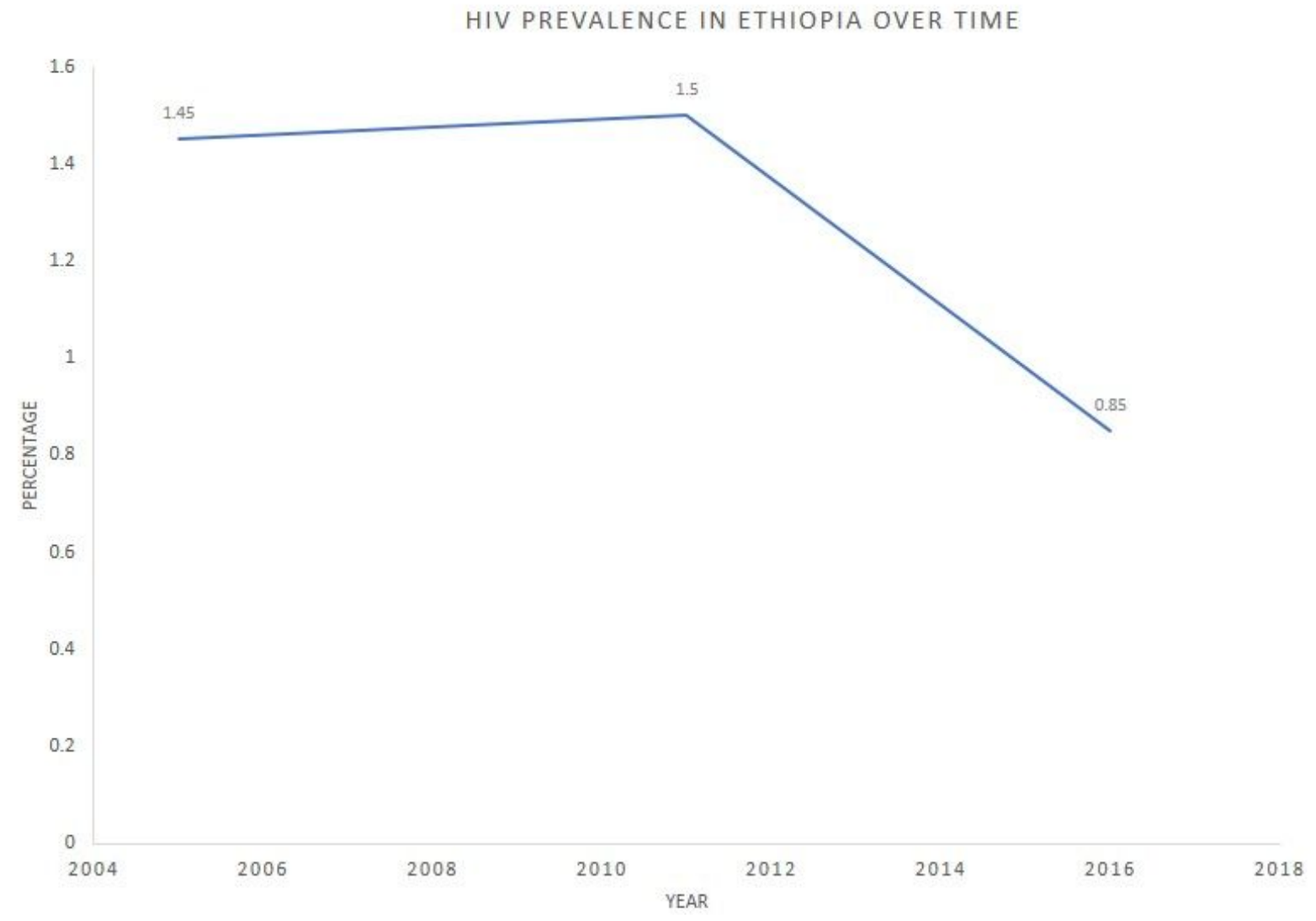

Figure 1

Trend of HIV prevalence among reproductive age group women in Ethiopia from 2005 to 2016. 


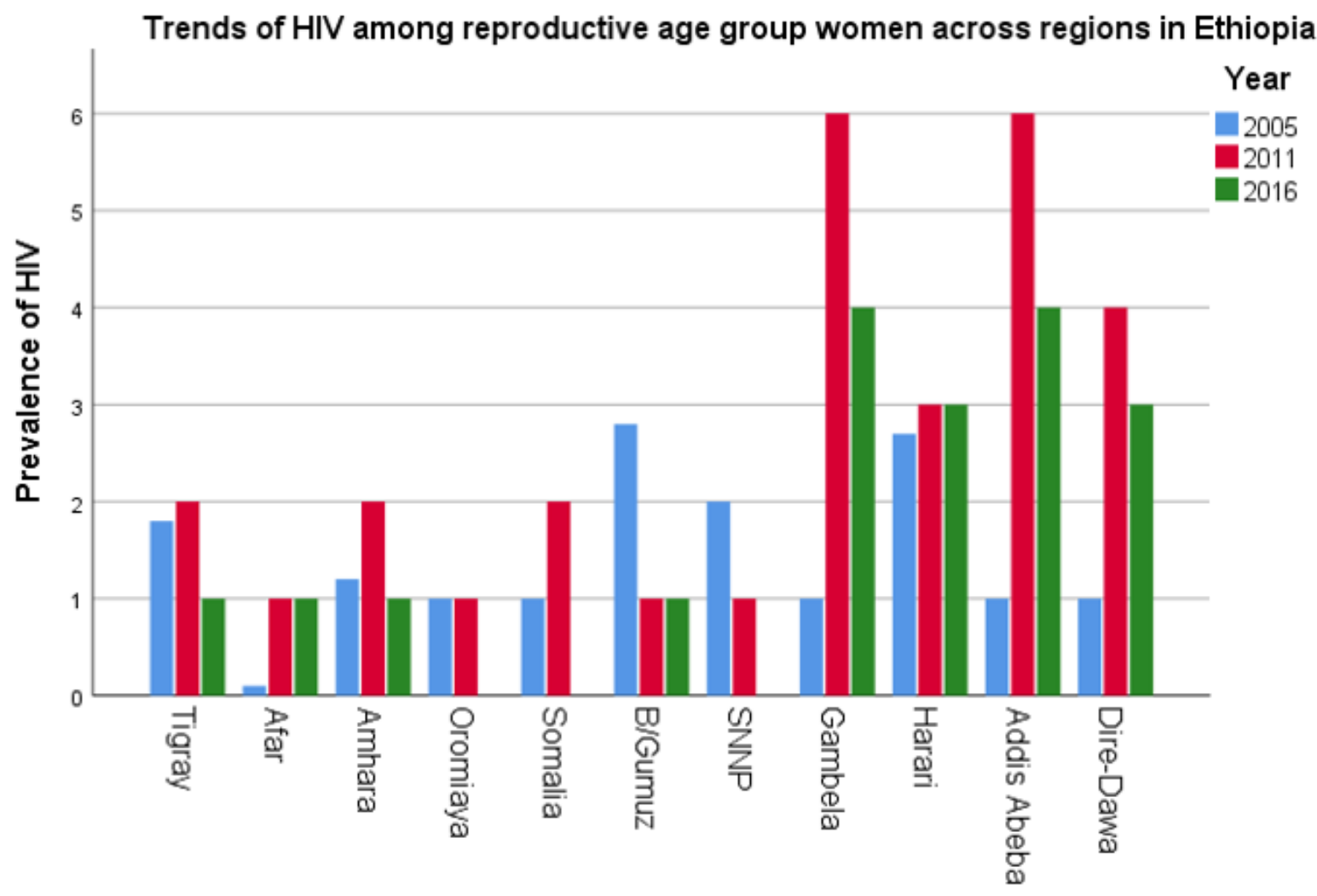

Region

Figure 2

The trends of HIV prevalence among reproductive age group women over time across regions in Ethiopia from 2005 to 2016. 